\title{
The Impact of Sexual Life Determinants on the Quality of Life of Moroccan Breast and Lung Cancer Survivors Two Years after Diagnosis
}

\author{
Rachid Ismaili ${ }^{1,}$, Ahmed Nejmeddine ${ }^{1}$, Hind Mimouni ${ }^{1}$, Imane El Haouachim ${ }^{2}$, Abderraouf Hilali ${ }^{1}$, \\ Bouchra Haddou Rahou ${ }^{3}$, Rachid Bekkali ${ }^{2}$ Leila Loukili ${ }^{1}$ \\ ${ }^{1}$ Hassan First University of Settat, Morocco \\ ${ }^{2}$ Foundation Lalla Salma Prevention and Treatment of Cancers, Rabat, Morocco \\ ${ }^{3}$ Research Department, High Institute of Nursing Professions and Technical Health, Rabat, Morocco
}

Received October 31, 2021; Revised December 17, 2021; Accepted January 16, 2022

\section{Cite This Paper in the following Citation Styles}

(a): [1] Rachid Ismaili, Ahmed Nejmeddine, Hind Mimouni, Imane El Haouachim, Abderraouf Hilali, Bouchra Haddou Rahou, Rachid Bekkali, Leila Loukili1, "The Impact of Sexual Life Determinants on the Quality of Life of Moroccan Breast and Lung Cancer Survivors Two Years after Diagnosis," Universal Journal of Public Health, Vol. 10, No. 1, pp. 43 - 52, 2022. DOI: 10.13189/ujph.2022.100105.

(b): Rachid Ismaili, Ahmed Nejmeddine, Hind Mimouni, Imane El Haouachim, Abderraouf Hilali, Bouchra Haddou Rahou, Rachid Bekkali, Leila Loukili1 (2022). The Impact of Sexual Life Determinants on the Quality of Life of Moroccan Breast and Lung Cancer Survivors Two Years after Diagnosis. Universal Journal of Public Health, 10(1), 43 - 52. DOI: 10.13189/ujph.2022.100105.

Copyright $\odot 2022$ by authors, all rights reserved. Authors agree that this article remains permanently open access under the terms of the Creative Commons Attribution License 4.0 International License

\begin{abstract}
Background: The consequences of therapeutic interventions for cancer have a negative impact on the patient's relationship and sexuality with his spouse. Purpose: This study aimed to investigate the impact of sexual life determinants on quality of life in Moroccan survivors of breast and lung cancers two years after diagnosis. Methods: This cross-sectional study was conducted between May 1, 2019 and September 30, 2020. The sample consists of 304 breast cancer survivors and 77 lung cancer survivors. Data were collected using EORTC QLQ - C30 questionnaire and questions on the sexual life component inspired by the living conditions questionnaire. Results: The GHS/QOL of lung cancer survivors as well as the physical, role, and emotional functional scales are severely impaired compared to those of breast cancer survivors. In contrast, social and cognitive functions were good for both types of cancer. In addition, there is a significant correlation between the GHS/QOL of survivors of both cancers and the effect of health status on the couple's relationship and the negative effect of the disease on the sexual relationship. Whereas, the GHS/QOL of breast cancer participants also correlated with spouse change. The effect of health status on couple's relationship
\end{abstract}

$(p=0.000)$ and negative effect of disease on sexual relationship $(\mathrm{p}=0.000)$ were significant predictors of GHS/QoL (QLQ-C30) in breast cancer survivors. Whereas, the negative effect of disease on sexual relationship $(p=0.020)$ was a significant predictor of GHS/QoL (QLQ-C30) in lung cancer survivors. Conclusion: The data suggest that sexual health education should be integrated into Medical and nursing curricula. In addition, health professionals should include an assessment of the effects of medical and surgical treatments on the sexuality of breast and lung cancer survivors.

Keywords Breast Cancer, Lung Cancer, Quality of Life, Impact, QLQ-C30, Living Conditions

\section{Introduction}

Advances in early detection and treatment of cancer imply that the number of survivors continues to increase, and, as a result, there has been an increased awareness of survival issues [1]. Many of these problems have an impact 
on the sexual function that is induced by cancer therapies such as surgery, chemotherapy, radiotherapy, and hormone therapy [1], [2]. Indeed, regardless of the type of therapies adopted, body image will be affected and often linked to other dysfunctions such as those associated with sexual dysfunction in women with breast cancer [3]. A total breast mastectomy and the scars after surgery have an impact on self-confidence and sexual desire [4], more life disruptions and significantly lower scores in body image, role and sexual domains [5]. In addition, a previous study found that factors impacting breast cancer survivors' sex lives include age, religious beliefs, treatment, and communication with sexual partners [6]. In other words, breast cancer survivors' quality of life is affected by pain, fear of recurrence, fatigue, depression, feelings of diminished femininity and attractiveness, and changes in body image, self-esteem and sexuality [7], [8]. In addition, physical intimacy has health benefits. Touching or hugging can lead to the release of oxytocin, dopamine, serotonin and reduce stress [9]. Estimates of sexual problems range from $40 \%$ to $100 \%$ after treatment for all types of cancer [10]. These dysfunctions can develop at any time during the disease [11]. There are sexual problems that usually do not resolve in the first two years of disease-free survival but may remain constant and relatively severe [12]. A previous study showed that organ loss or scarring, treatment-related hair loss, and weight gain were the symptoms that affected body image [13]. In addition, breast cancer treatment leads to physical sexual problems, such as vaginal lubrication, decreased nipple sensation, and decreased desire due to treatment-induced menopause [14]. These sexual problems are common, with an estimated prevalence of 85\% [6], [15]. In terms of quality of life, sexual functioning is a crucial aspect for women with breast cancer [16]. Multivariate analysis of a cross-sectional survey of younger women found that mastectomy was related to problems with interest in sex and that chemotherapy was associated with sexual dysfunction [17]. In addition, the use of Tamoxifen-type hormone therapy for one year was associated with vaginal dryness, bone pain, and sleep disturbance [18].

As for lung cancer, which is the leading cause of cancer deaths in the world with 1.80 million deaths [19]. Factors that may favor the diagnosis of advanced lung cancer include lack of insurance and gender (female). On the other hand, the protective factors were marital status (single) and the place of residence (rural) [20]. Data revealed that up to $95 \%$ of lung cancer patients have a sexual function score below the fiftieth percentile during and after the end of treatment, and problems related to sexual dysfunction persist and do not improve with time [21], [22]. Studies have shown that the impact of lung cancer treatment on sexual function is distressing, and sexual concerns are related to symptoms and poorer functional status [23], [24]. Because of the low survival rates for lung cancer, with $41 \%$ of patients surviving after one year and only $15 \%$ surviving after five years [23], and because overall survival rates at 1 and 5 years were $31.7 \%$ and $3.4 \%$, respectively [25], very little research on sexual functioning has been done [9], [22]. Therefore, little is known about the impact of lung cancer on intimate and sexual relationships [9]. The present study aims to investigate the impact of sexual life determinants on quality of life in Moroccan survivors of breast and lung cancers two years after their diagnosis and who are treated at the NIO in Rabat. The data obtained constitute a database on breast and lung cancers and may expose findings that will eventually help other authors in different breast and lung cancer research.

\section{Materials and Methods}

\section{Study Design}

This is a cross-sectional study investigating the impact of sexual life determinants on the quality of life of Moroccan breast and lung cancer survivors treated at NIO in Rabat, and who were diagnosed at two years for breast cancer and between two and 18 months for lung cancer. Three hundred and eighty-one (381) breast and lung cancer survivors were recruited during their follow-up consultation at NIO in Rabat between May 1, 2019 and September 30, 2020. This work is part of a thesis entitled: «The social cost of cancer: Impact of breast and lung cancers on the quality of life of the patient and his/her nuclear family after two years of diagnosis».

Inclusion criteria: The study included all survivors of breast and lung cancers diagnosed two years earlier for breast cancer and between two years and 18 months for lung cancer and who are treated at NIO Rabat, married with children and at all disease stages.

Exclusion Criteria: All single survivors, survivors with a history of physical or mental disorders or other types of conditions other than breast and lung cancer.

\section{Data Collection:}

Eligible participants for the study consist of $80 \%$ breast cancer survivors and $20 \%$ lung cancer survivors. They are recruited by the designated nurse interviewer at the consultation unit. The investigator verified the inclusion criteria, answered the survivors' questions, and re-solicited their consent to participate. Once consent was obtained from the participants, clear information about the study and its objectives were provided.

\section{Ethical considerations}

In order to carry out this research, authorization was obtained from the Ethics Committee for Biomedical Research Mohammed V University (Rabat Faculty of Medicine and Pharmacy, Rabat Faculty of Dental Medicine), (N/R: Folder Number 63/19), and data collection was carried out after obtaining informed written 
consent from each participant.

\section{Instruments}

In order to meet the above objective, data are collected through the generic EORTC QLQ-C30 questionnaire, which is specifically designed for cancer patients. The cross-cultural adaptation of this questionnaire was made and validated in Morocco [26], [27].

\section{EORTC QLQ-30 questionnaire}

In 1986, this instrument was designed by the European Treatment Research Organization. It has been validated in many tumor locations. And tested in the United States, Australia, Europe, and Japan and has demonstrated high reliability and validity on all continents [28], [29]. The questionnaire consists of 30 items, each rated on a 4-point Likert scale, except for the overall quality of life items with a 7-point response format. The 30 items are summarized into a global quality of life scale, five functioning scales (physical function, role function, emotional function, cognitive function, and social function), and nine symptom scales. In addition, a summary score for the QLQ-C30 was recently introduced to complete the 15-outcome profile [30]. The dimensions explored include between one and five different items. The results of these different scales are used to calculate a score out of 100 , which is illustrated in the procedure described in the EORTC QLQ-30 scoring manual. A high score for a functional scale reflects an optimal function of the measured variables. On the other hand, a high score for a symptomatic scale reflects a high level of symptoms. Furthermore a high overall health score explains a good health status and quality of life.

\section{Questionnaire to explore sexual life component}

In order to explore the sexual life component, the study used several questions inspired by the living conditions questionnaire used by previous research [31], [32].

\section{Statistical analysis}

A descriptive analysis of the socio-demographic situation and sexual life was performed with the calculation of statistical parameters such as numbers and percentages. A simple linear regression model was applied to detect the association between GHS/QOL and some determinants of sexual life. Variables with $\mathrm{p} \leq 0.20$ in univariate analysis were included in the regression model to assess predictors of overall health-related quality. All confounding variables were included in the multivariate analysis. The variables are considered significant if $\mathrm{p} \leq$ 0.05. Scoring of the EORTC QLQ-C30 items was performed according to the EORTC scoring manual [28]. In the case of missing items, multi-items scores were calculated as the mean of non-missing items if at least half of the items from the corresponding scale had been completed. Statistical analysis was performed using the SPSS software. The study defined survivors with problematic functioning as those who scored $<33.3 \%$, whereas survivors with good quality scored $\geq 66.7 \%$. Conversely, survivors with more severe symptoms scored $\geq 66.7 \%$ for the symptom scales, while those scoring $<33.3 \%$ were considered with less severe symptoms [33].

\section{Results}

\section{(1) Description of the study population}

A total of 381 survivors were included in the study, of whom 304 had breast cancer, and 77 had lung cancer. The mean age was $57.05 \pm 14.49$, and the female sex was represented in $60.4 \%$ of the cases. $44.2 \%$ of survivors were illiterate, and $55 \%$ were inactive. Survivors with no monthly income before the disease represent $48 \%$ and $30 \%$ for those with a monthly income below 2500 DHS. More than half of the survivors were affiliated with the RMED (62\%); the rest are divided between the CNOPS, CNSS, and insurance with a percentage of $25 \%, 10 \%$, and $2 \%$, respectively. The description of the socio-demographic characteristics is shown in Table 1.

\section{(2) Description of the dimensions of the EORTC QLQ C-30 breast and lung cancer scale}

Reading the results in Table 2, the mean global health score $(23.9 \pm 23.9)$ of lung cancer survivors was much worse than that of breast cancer survivors (57.2 \pm 25.4$)$. The mean scores of the different functional dimensions of the QLQ-C30 questionnaire for breast cancer survivors ranged from 51.2 to 84.5 and for lung cancer survivors from 27.7 to 72.1. The "Emotional Function" dimension appeared to be the most impaired in breast cancer survivors, whereas the "Social Function" dimension was the least affected. While in lung cancer survivors, the dimensions "Role function" and "Physical function" were the most impaired. In contrast, the "Social Function" dimension was the least impaired. As for the symptom dimensions, financial problems were common with mean scores of $(75.3 \pm 35.2)$ for lung cancer survivors and (54.1 \pm 39.9$)$ for breast cancer survivors. In addition, the mean scores for the symptoms of fatigue, insomnia, pain, dyspnea, and loss of appetite were significantly impaired ((71.7 \pm 33.7$), \quad(62.8 \pm 37.5)$, (61.9 \pm 38.4$)$, (58.4 \pm 42.6$)$, $(54.5 \pm 41.1)$ respectively)) for the majority of lung cancer survivors. In contrast, these symptoms are virtually absent in most breast cancer survivors (Table 2). 

and Lung Cancer Survivors Two Years after Diagnosis

Table 1. Socio-demographic characteristics of the study population

\begin{tabular}{|c|c|c|c|c|c|}
\hline \multicolumn{2}{|c|}{ Characteristics } & \multicolumn{2}{|c|}{ Breast } & \multicolumn{2}{|c|}{ Lung } \\
\hline \multirow{6}{*}{ Age } & & Number & Percentage & Number & Percentage \\
\hline & & \multicolumn{4}{|c|}{ Average (57.05 \pm 14.49$)$} \\
\hline & Under 25 years old & 4 & 1.3 & 00 & 00 \\
\hline & 26 to 45 years old & 90 & 29.6 & 4 & 5.2 \\
\hline & 46 to 65 years old & 188 & 61.8 & 58 & 75.3 \\
\hline & Over 65 years old & 22 & 7.2 & 15 & 19.5 \\
\hline \multirow{2}{*}{ Gender } & Man & 00 & 00 & 61 & 79.2 \\
\hline & Woman & 304 & 100 & 16 & 20.8 \\
\hline \multirow{2}{*}{ Place of residence } & Urban & 212 & 69.7 & 57 & 74.0 \\
\hline & Rural & 91 & 29.9 & 20 & 26.0 \\
\hline \multirow{4}{*}{ Level of education } & Illiterate & 158 & 52.0 & 28 & 36.4 \\
\hline & Primary & 82 & 27.0 & 23 & 29.8 \\
\hline & Secondary & 46 & 15.1 & 22 & 28.6 \\
\hline & Superior & 17 & 5.6 & 4 & 5.2 \\
\hline \multirow{3}{*}{ Marital status } & Married & 304 & 100 & 69 & 89.6 \\
\hline & Widower & 00 & 00 & 5 & 6.5 \\
\hline & Divorced & 00 & 00 & 3 & 3.9 \\
\hline \multirow{2}{*}{ Professional status } & Active & 76 & 25.0 & 50 & 64.9 \\
\hline & Inactive & 228 & 75.0 & 27 & 35.1 \\
\hline \multirow{4}{*}{ Social security } & RAMED & 208 & 68.4 & 43 & 55.8 \\
\hline & CNOPS & 62 & 20.4 & 23 & 29.9 \\
\hline & CNSS & 31 & 10.2 & 8 & 10.4 \\
\hline & Insurance & 1 & 0.3 & 3 & 3.9 \\
\hline \multirow{4}{*}{$\begin{array}{l}\text { Monthly income before } \\
\text { illness }\end{array}$} & No income & 132 & 43.4 & 40 & 51.9 \\
\hline & Less than $2500 \mathrm{DH}$ & 115 & 37.5 & 17 & 22.1 \\
\hline & Between $2501 \mathrm{DH}$ and $5000 \mathrm{DH}$ & 42 & 13.8 & 18 & 23.4 \\
\hline & Between $5001 \mathrm{DH}$ and $7500 \mathrm{DH}$ & 11 & 3.6 & 2 & 2.6 \\
\hline
\end{tabular}

RAMED: Insurance for low-income patients; CNOPS: National Fund for Social Security Organizations; CNSS: National Social Security Fund. 
Table 2. EORTC-QLQ-C30 Scores and Perceived Level of Quality of Life by Breast and Lung Cancer Survivors

\begin{tabular}{|c|c|c|c|c|c|c|c|c|c|c|c|}
\hline \multirow[b]{2}{*}{ EORTC-QLQ-C30 Variables } & \multicolumn{6}{|c|}{ Breast } & \multicolumn{5}{|c|}{ Lung } \\
\hline & $\begin{array}{c}\text { No } \\
\text { Of items }\end{array}$ & $\begin{array}{c}\text { Bad } \\
<33.3 \% \\
\end{array}$ & $\begin{array}{c}\text { Average } \\
33.3 \%-66.6 \% \\
\end{array}$ & $\begin{array}{c}\text { Good } \\
\geq 66.7 \% \\
\end{array}$ & Mean & $\begin{array}{l}\text { Standard } \\
\text { Deviation }\end{array}$ & $\begin{array}{c}\mathrm{Bad} \\
<33.3 \% \\
\end{array}$ & $\begin{array}{c}\text { Average } \\
33.3 \%-66.6 \% \\
\end{array}$ & $\begin{array}{c}\text { Good } \\
\geq 66.7 \% \\
\end{array}$ & Mean & $\begin{array}{l}\text { Standard } \\
\text { Deviation }\end{array}$ \\
\hline $\begin{array}{l}\text { Global health status/QoL } \\
\text { Global health status/QoL }\end{array}$ & 2 & $41(13.5)$ & 101(33.2) & $162(53.3)$ & 57.2 & 25.4 & $43(55,8)$ & $27(35,1)$ & $27(9,1)$ & 23,91 & 23,92 \\
\hline \multicolumn{12}{|c|}{ Functional scales } \\
\hline Physical functioning & 5 & 29(9.5) & $54(17.8)$ & $219(72.0)$ & 72.6 & 28.0 & $45(59,2)$ & $7(9,2)$ & $24(31,6)$ & 31,7 & 35,2 \\
\hline Role functioning & 2 & $27(8.9)$ & $51(16.8)$ & $220(72.4)$ & 71.8 & 31.2 & $47(61,0)$ & $8(10,4)$ & $22(28,6)$ & 27,7 & 36,9 \\
\hline Emotional functioning & 4 & $79(26.0)$ & $98(32.2)$ & $119(39.1)$ & 51.2 & 31.3 & 25(32.5) & $21(27.3)$ & $31(40.3)$ & 45.3 & 34.3 \\
\hline Cognitive functioning & 2 & $27(8.9)$ & 41(13.5) & $225(74.0)$ & 78.4 & 30.5 & $12(15.6)$ & 13(16.9) & $52(67.5)$ & 70.3 & 32.9 \\
\hline Social functioning & 2 & $25(8.2)$ & $14(4.6)$ & $265(87.2)$ & 84.5 & 29.3 & $10(13,0)$ & $5(6,5)$ & $62(80,5)$ & 72,1 & 32,8 \\
\hline \multicolumn{12}{|c|}{ Symptom scales / items } \\
\hline Fatigue & 3 & $138(45.4)$ & $107(35.2)$ & $46(15.1)$ & 33.3 & 30.1 & $7(9,1)$ & $25(32,5)$ & $45(58,4)$ & 71,7 & 33,7 \\
\hline Nausea and vomiting & 2 & $250(82.2)$ & $23(7.6)$ & $31(10.2)$ & 11.7 & 26.5 & $43(55.8)$ & $15(19.5)$ & $19(24.7)$ & 29.0 & 37.0 \\
\hline Pain & 2 & $135(44.4)$ & $87(28.6)$ & $76(25.0)$ & 34.3 & 32.6 & $16(20,8)$ & $17(22,1)$ & $44(57,1)$ & 61,9 & 38,4 \\
\hline Dyspnoea & 1 & $169(55.6)$ & 19(6.3) & $116(38.2)$ & 32.0 & 38.7 & $21(27,3)$ & $11(14,3)$ & $45(58,4)$ & 58,4 & 42,6 \\
\hline Insomnia & 1 & $175(57.6)$ & 43(14.1) & $85(28.0)$ & 27.9 & 37.1 & $14(18,2)$ & $11(14,3)$ & $52(67,5)$ & 62,8 & 37,5 \\
\hline Appetite loss & 1 & 210(69.1) & $38(12.5)$ & $56(18.4)$ & 19.3 & 32.6 & $23(29,9)$ & $8(10,4)$ & $46(59,7)$ & 54,5 & 41,1 \\
\hline Constipation & 1 & 245(80.6) & $18(5.9)$ & $41(13.5)$ & 12.9 & 28.8 & $47(61.0)$ & $1(1.3)$ & 29(37.7) & 30.7 & 40.4 \\
\hline Diarrhoea & 1 & 236(77.6) & $32(10.5)$ & $34(11.2)$ & 12.1 & 25.6 & $53(68.8)$ & $3(3.9)$ & $21(27.3)$ & 22.5 & 35.6 \\
\hline Financial difficulties & 1 & $75(24.7)$ & $64(21.1)$ & $157(51.6)$ & 54.1 & 39.9 & $5(6,5)$ & $20(26,0)$ & $52(67,5)$ & 75,3 & 35,2 \\
\hline
\end{tabular}




\section{(3) Description of survivors' sexual outcomes by cancer type}

The data in Table 3 revealed that most of the study population (84\%) was living with a partner at the time of the survey. For breast cancer survivors, $68 \%$ were in a relationship with the same person at the time of diagnosis, with $45 \%$ of survivors reporting that their relationship had deteriorated and $19 \%$ confirming that their illness had strengthened their relationship. $45 \%$ of the survivors stated that the disease had negatively impacted their sexual relationship and $16 \%$ faced negative effects from time to time. In $45 \%$ of the cases, the change was related to attitudes toward sex, whereas $19 \%$ were related to the quality of the relationship.

Among lung cancer survivors, $78 \%$ were in a relationship with the same person at the time of diagnosis, with $10 \%$ claiming that their relationship had deteriorated. While $61 \%$ of the survivors stated that their relationship had remained the same, only $14 \%$ confirmed that their relationship was strengthened. $53 \%$ of the survivors revealed that the disease has negatively impacted their sexual relationship and16\% reported negative effects from time to time. On the other hand, $14 \%$ of survivors had no change in their sexual relationship. The state of health induced this change in $56 \%$ of cases, $8 \%$ by an attitude towards sexuality, and $5 \%$ by the quality of the couple's relationship.

\section{(4) Univariate and multivariate linear regression analysis between GHS/QoL (QLQ-C30) and sexual life in breast and lung cancer survivors}

Analysis of the results in Table 4 reveals a significant association between GHS/QoL and some determinants of the sexual lives of breast and lung cancer survivors. For breast cancer survivors, the correlated variables were changed in spouse ( $\mathrm{p}=0.024)$, the effect of health status on the couple's relationship $(\mathrm{p}=0.000)$, and the negative effect of the disease on the sexual relationship $(\mathrm{p}=0.050)$. Regarding lung cancer survivors, the correlated variables were the effect of health status on the couple's relationship $(p=0.041)$ and the negative effect of the disease on the sexual relationship $(p=0.021)$.

Table 3. Survivors' sexual life changes by cancer type

\begin{tabular}{|c|c|c|c|c|c|}
\hline \multirow{2}{*}{ Questions } & & \multicolumn{2}{|c|}{ Breast } & \multicolumn{2}{|c|}{ Lung } \\
\hline & & Number & Percentage & Number & Percentage \\
\hline \multirow{2}{*}{$\begin{array}{c}\text { Are you currently living in } \\
\text { a couple? }\end{array}$} & Yes & 255 & 84 & 66 & 83 \\
\hline & No & 49 & 16 & 6 & 8 \\
\hline \multirow{2}{*}{$\begin{array}{l}\text { When you knew you had } \\
\text { the disease, were you in a } \\
\text { relationship? }\end{array}$} & Yes & 301 & 99 & 67 & 84 \\
\hline & No & 3 & 1 & 4 & 5 \\
\hline \multirow{2}{*}{$\begin{array}{l}\text { If yes, are you currently in } \\
\text { a relationship with the } \\
\text { same person at the time of } \\
\text { diagnosis? }\end{array}$} & Yes & 206 & 68 & 62 & 78 \\
\hline & No & 64 & 21 & 4 & 5 \\
\hline \multirow{3}{*}{$\begin{array}{l}\text { If yes, is your } \\
\text { relationship? }\end{array}$} & Deteriorated & 138 & 45 & 8 & 10 \\
\hline & Remained the same & 54 & 18 & 49 & 61 \\
\hline & Strengthened & 58 & 19 & 11 & 14 \\
\hline \multirow{3}{*}{$\begin{array}{c}\text { Given your health } \\
\text { condition, do you think } \\
\text { your relationship has been } \\
\text { influenced? }\end{array}$} & No & 54 & 18 & 42 & 53 \\
\hline & Negatively & 137 & 45 & 9 & 11 \\
\hline & Positively & 58 & 19 & 19 & 24 \\
\hline \multirow{3}{*}{$\begin{array}{l}\text { Do you think your illness } \\
\text { has a negative impact on } \\
\text { your sexual relationship? }\end{array}$} & Yes, a lot of & 137 & 45 & 42 & 53 \\
\hline & Yes, occasionally & 54 & 18 & 13 & 16 \\
\hline & No, not at all & 58 & 19 & 11 & 14 \\
\hline \multirow{3}{*}{$\begin{array}{l}\text { If your sexual relationship } \\
\text { has changed, do you think } \\
\text { it is? }\end{array}$} & Changing the quality of your relationship & 58 & 19 & 4 & 5 \\
\hline & Changes in your attitude towards sexuality & 136 & 45 & 6 & 8 \\
\hline & A reason related to your health condition & 00 & 00 & 45 & 56 \\
\hline
\end{tabular}


Table 4. Univariate and multivariate linear regression between GHS/QoL (QLQ-C30) and sexual life of breast and lung cancer survivors

\begin{tabular}{|c|c|c|c|c|c|c|c|c|c|c|}
\hline \multirow{4}{*}{$\begin{array}{c}\text { Independent } \\
\text { Variable }\end{array}$} & \multicolumn{10}{|c|}{ Global health status } \\
\hline & \multicolumn{5}{|c|}{ Lung cancer } & \multicolumn{5}{|c|}{ Breast cancer } \\
\hline & \multicolumn{2}{|c|}{$\begin{array}{c}\text { Univariate } \\
\text { analysis }\end{array}$} & \multicolumn{3}{|c|}{ Multivariate analysis } & \multicolumn{2}{|c|}{$\begin{array}{c}\text { Univariate } \\
\text { analysis }\end{array}$} & \multicolumn{3}{|c|}{ Multivariate analysis } \\
\hline & $\beta$ & $\mathrm{P} v$ & $\beta$ & $\mathrm{P} v$ & {$[95.0 \% \mathrm{CI}]$} & $\beta$ & $\mathrm{P} v$ & $\beta$ & $\mathrm{Pv}$ & {$[95.0 \% \mathrm{CI}]$} \\
\hline $\begin{array}{l}\text { In a relationship at } \\
\text { the time of diagnosis }\end{array}$ & 0.132 & 0.270 & ----- & ----- & ------------ & -0.081 & 0.158 & $\begin{array}{c}-0.10 \\
6 \\
\end{array}$ & 0.142 & [-44.61 to 6.42$]$ \\
\hline $\begin{array}{l}\text { In a relationship at } \\
\text { the time of the study }\end{array}$ & -0.030 & 0.800 & ---- & ----- & ------------ & 0.058 & 0.312 & ----- & ----- & ----------- \\
\hline Change of spouse & -0.014 & 0.909 & ---- & ---- & ------------ & 0.137 & 0.024 & 0.039 & 0.536 & [-5.54 to 10.63$]$ \\
\hline $\begin{array}{l}\text { The effect of health } \\
\text { status on the couple's } \\
\text { relationship }\end{array}$ & -0.245 & 0.041 & -0.118 & 0.399 & [-10.33 to 4.18$]$ & 0.265 & 0.000 & 0.382 & 0.000 & [9.96to 20.54] \\
\hline $\begin{array}{l}\text { Negative effect of } \\
\text { the disease on the } \\
\text { sexual relationship }\end{array}$ & 0.284 & 0.021 & 0.328 & 0.020 & [2.68 to 29.72] & -0.124 & 0.050 & $\begin{array}{c}-0.29 \\
6\end{array}$ & 0.000 & [-14.05 to -5.36$]$ \\
\hline $\begin{array}{l}\text { Reason for change in } \\
\text { sexual life }\end{array}$ & -0.076 & 0.572 & ----- & ----- & ------------ & 0.095 & 0.188 & 0.106 & 0.141 & [-0.91 to 6.35$]$ \\
\hline
\end{tabular}

Multivariate analysis unveiled that the effect of health status on the couple's relationship $(p=0.000)$ and the negative effect of the disease on the sexual relationship $(p=0.000)$ were significant predictors of $\mathrm{GHS} / \mathrm{QoL}$ (QLQ-C30) in breast cancer survivors. In contrast, the negative effect of disease on the sexual relationship $(\mathrm{p}=0.020)$ was a significant predictor of $\mathrm{GHS} / \mathrm{QoL}$ (QLQ-C30) in lung cancer survivors.

\section{Discussion}

To our knowledge, this is the first study conducted in Morocco entitled "Impact of sexual life determinants on the quality of life of Moroccan survivors of breast cancer diagnosed two years earlier and of lung cancer diagnosed between eighteen months and two years earlier". There are studies in Morocco that have addressed the quality of life or sexuality of cancer patients at the time of diagnosis or at the end of treatment [34]-[38]. The results obtained from this study show that more than half of the breast cancer participants had a mean global QoL score (57.2 25.4 ), which is similar to the mean global QoL score of metastatic breast cancer (57.6 \pm 23.1 ), and lower than the mean score for early breast cancer (76.9 \pm 19.2$)$ [39], and the mean score of the reference values (RV) for breast cancer at any stage (61.8 \pm 24.6$)$ [40]. Besides, physical, social, and emotional functions had lower values than the EORTC QLQ-C30 reference for early breast cancer [39]. In addition, the mean RV scores of physical, emotional, and cognitive function are better than those in the present study. In contrast, the survivors' mean scores of role and social function are better than those of the RV [40], and the participants' role, physical and emotional functional scales are worse than those of Kristin $\mathrm{H}$ et al. [41].

As for the symptom scale, most of the mean scores in RV are better than those in the present study [40]. Similarly, the data revealed poor overall quality of life in $55.8 \%$ of lung cancer survivors with a mean score of $(23.91 \pm 23.92)$. This result is much lower than the reference values for lung cancer at any stage (56.6 \pm 24.3$)$ [40]. Physical and role functioning scales are degraded. These data seem similar to the results found in previous research [42]-[44]. In addition, the mean scores of physical, role, emotional, and cognitive function of the survivors are worse than those of the reference values. On the other hand, the mean score of the social function of the survivors is better than that of the RV. Furthermore, all participants' mean symptom scores were significantly worse than those of the RV [40]. These results corroborate with Yang et al; who confirmed that long-term lung cancer survivors exhibited impaired QoL and increased symptom burden [45]. The most common symptoms among lung cancer survivors were fatigue, loss of appetite, insomnia, dyspnea, pain, and financial difficulties. These findings are consistent with data from a previous study [46]. In addition, fatigue, coughing, pain, and insomnia have been reported in previous research as common symptoms in lung cancer survivors, which often worsen over time and are related to poor quality of life [45]-[49]. In terms of comparison between the two types of cancer studied, the results showed that breast cancer survivors' physical and role functions were better than those of lung cancer survivors. However, the emotional function was similarly impaired in survivors of both cancers. Moreover, cognitive and social functions were similarly good in all participants. In other words, all scales of functioning, as well as symptoms of the lung cancer participants, are significantly impaired compared to a previous study [43]. Indeed, it is widely recognized that cancer and its treatment significantly affect the quality of life [47], in this case, sexual functioning and intimacy [2]. In addition, they can cause a loss of confidence about sexual attractiveness, create substantial changes in body image, perception and apprehension about intimate 
relationships, and sometimes fear of pain or fear of doing wrong can prevent the partner from a sexual relationship [48]. The study results revealed that $45 \%$ of breast cancer survivors experience negative effects on their sexual relationship, and $16 \%$ experience negative effects occasionally. Several studies have shown that sexual problems are common after breast cancer treatment, with an estimated prevalence of up to $85 \%$ [6], [15], [49]. As a result, women with breast cancer and their partners frequently experience negative changes in their relationship and sexuality [48]-[51]. 45\% of the participants in the study linked this change to their attitude toward sexual relationship and $19 \%$ to the quality of the relationship. Among lung cancer survivors, 53\% reported that their health condition negatively impacted their sexual relationship, and $16 \%$ had adverse effects occasionally. These data are consistent with studies who have estimated that sexual dysfunction affects $40 \%$ to $100 \%$ of people with lung cancer [50], and that most problems related to sexual dysfunction persist rather than improve over time [21]. These sexual dysfunctions were attributed in $56 \%$ to the health status of the participants, $8 \%$ to the attitude towards sex. In a previous study, most survivors reported at least a slight change in their sexual life, clearly indicating an impact of cancer and its treatment on sexuality [51].

Univariate analysis revealed a significant association between GHS/QOL and the effect of health status on the couple's relationship, as well as the negative effect of the disease on the sexual relationship in breast and lung cancer survivors. This is consistent with the results found in previous studies that indicated that the disease had a significantly negative impact on sexual functioning and intimate relationship [13], [51], [52]. In comparison, the variable of spousal change correlated only with GHS/QOL in breast cancer survivors. The multivariate analysis stated that the effect of health status on couple relationships $(p=0.000)$ and the negative effect of illness on the sexual relationship $(\mathrm{p}=0.000)$ were significant predictors of GHS/QoL (QLQ-C30) in breast cancer survivors. In contrast, the negative effect of disease on the sexual relationship $(\mathrm{p}=0.020)$ was a significant predictor of GHS/QoL (QLQ-C30) in lung cancer survivors. In sum, it was not possible to make a deeper comparison between the data obtained and those arising from research carried out in other countries because of the cultural, social, and moral context that greatly condition sexual behavior, since the sexual impact of cancer and its treatment has long been a taboo subject in clinical settings in Morocco [37]. This study has some limitations. First, the research sample was limited to breast and lung cancer participants, and healthy individuals with these conditions were not studied. Secondly, the homogeneity of the study is due to the inclusion of participants with different types of diagnoses. Third, this study was based on a single tertiary oncology center, so the data could not be generalized to the population of people with breast and lung cancers in Morocco.

\section{Conclusion}

This study showed that lung cancer survivors' overall quality of life was significantly impaired compared to breast cancer survivors. The same was true for all EORTC QLQ-C30 functional scales, except for cognitive and social function, which were slightly good. In addition, the majority of symptoms in lung cancer participants were significantly worsened compared to breast cancer participants, except for financial difficulty, which was impaired in all patients. In addition, some determinants of sexual life were strongly associated with GHS/QOL, namely the effect of health status on the couple's relationship and the negative effect of the disease on the sexual relationship in breast and lung cancer survivors. In sum, the negative effect of disease on the sexual relationship was the significant predictor of GHS/QOL in both cancer types, whereas the effect of health status on the couple's relationship was the significant predictor of GHS/QOL only for breast cancer survivors.

Results suggest that sexual health education should be integrated into Medical and nursing curricula. Develop support strategies for survivors and their partners at oncology centers. In addition, health professionals should include an assessment of the effects of medical and surgical treatments on the sexuality of breast and lung cancer survivors. Therefore, medical staff should pay more attention to discussing sexual dysfunctions with the patient as part of the side effects experienced during the cancer treatment program.

\section{Acknowledgements}

We thank "Fondation Lalla Salma Prevention and Treatment of Cancers" and we acknowledge the study team for their important contributions towards this research. We thank the patients and families for their cooperation.

\section{REFERENCES}

[1] S. J. Falk and D. S. Dizon, 'Sexual dysfunction in women with cancer’, Fertil. Steril., vol. 100, no. 4, pp. 916-921, Oct. 2013, doi: 10.1016/j.fertnstert.2013.08.018.

[2] J. L. Wright, D. W. Lin, J. E. Cowan, P. R. Carroll, M. S. Litwin, and CaPSURE Investigators, 'Quality of life in young men after radical prostatectomy', Prostate Cancer Prostatic Dis., vol. 11, no. 1, pp. 67-73, 2008, doi: 10.1038/sj.pcan.4500980.

[3] C. L. Paterson, C. A. Lengacher, K. A. Donovan, K. E. Kip, and C. S. Tofthagen, 'Body Image in Younger Breast Cancer Survivors: A Systematic Review’, Cancer Nurs., vol. 39, no. 1, p. E39, Feb. 2016, doi: 10.1097/NCC. 0000000000000251 .

[4] Y.-C. Chang, W.-Y. Hu, Y.-M. Chang, and S.-C. Chiu, 
'Changes in sexual life experienced by women in Taiwan after receiving treatment for breast cancer', Int. J. Qual. Stud. Health Well-Being, vol. 14, no. 1, p. 1654343, Sep. 2019, doi: 10.1080/17482631.2019.1654343.

[5] E. N. Boswell and D. S. Dizon, 'Breast cancer and sexual function’, Transl. Androl. Urol., vol. 4, no. 2, Art. no. 2, Apr. 2015.

[6] Y.-C. Chang, S.-R. Chang, and S.-C. Chiu, 'Sexual Problems of Patients With Breast Cancer After Treatment: A Systematic Review', Cancer Nurs., vol. 42, no. 5, pp. 418-425, Oct. 2019, doi: 10.1097/NCC.000000000000059 2

[7] M. C. Lee et al., 'Therapy choices and quality of life in young breast cancer survivors: a short-term follow-up', Am. J. Surg., vol. 206, no. 5, pp. 625-631, Nov. 2013, doi: 10.1016/j.amjsurg.2013.08.003.

[8] B. H. L. Howes, D. I. Watson, C. Xu, B. Fosh, M. Canepa, and N. R. Dean, 'Quality of life following total mastectomy with and without reconstruction versus breast-conserving surgery for breast cancer: A case-controlled cohort study', $J$. Plast. Reconstr. Aesthetic Surg. JPRAS, vol. 69, no. 9, pp. 1184-1191, Sep. 2016, doi: 10.1016/j.bjps.2016.06.004.

[9] S. T. Lindau, H. Surawska, J. Paice, and S. R. Baron, 'Communication about sexuality and intimacy in couples affected by lung cancer and their clinical-care providers', Psycho oncology., vol. 20, no. 2, pp. 179-185, Feb. 2011, doi: 10.1002/pon.1787.

[10] L. R. Derogatis and S. M. Kourlesis, 'An approach to evaluation of sexual problems in the cancer patient', $C A$. Cancer J. Clin., vol. 31, no. 1, pp. 46-50, Feb. 1981, doi: 10.3322/canjclin.31.1.46.

[11] A. L. McKee and L. R. Schover, 'Sexuality rehabilitation', Cancer, vol. 92, no. 4 Suppl, pp. 1008-1012, Aug. 2001, doi:10.1002/1097-0142(20010815)92:4+<1008::aid-cncr1 413>3.0.co;2-2

[12] PDQ Supportive and Palliative Care Editorial Board, 'Sexuality and Reproductive Issues (PDQ $\left.{ }^{\circledR}\right)$ : Health Professional Version', in PDQ Cancer Information Summaries, Bethesda (MD): National Cancer Institute (US) 2002. Accessed: Jun. 23, 2021. [Online]. Available: http://www.ncbi.nlm.nih.gov/books/NBK65975/

[13] K. E. Flynn et al., 'Sexual Functioning Along the Cancer Continuum: Focus Group Results from the Patient-Reported Outcomes Measurement Information System (PROMIS ${ }^{\mathrm{TM}}$ )', Psychooncology., vol. 20, no. 4, pp. 378-386, Apr. 2011, doi: 10.1002/pon.1738.

[14] J. I. Arraras et al., 'Quality of life in elderly patients with localized breast cancer treated with radiotherapy. A prospective study', Breast Edinb. Scotl., vol. 26, pp. 46-53, Apr. 2016, doi: 10.1016/j.breast.2015.12.008.

[15] J. M. Ussher, J. Perz, and E. Gilbert, 'Information needs associated with changes to sexual well-being after breast cancer', J. Adv. Nurs., vol. 69, no. 2, pp. 327-337, Feb. 2013, doi: 10.1111/j.1365-2648.2012.06010.x.

[16] W. L. Ong et al., 'A Standard Set of Value-Based Patient-Centered Outcomes for Breast Cancer: The International Consortium for Health Outcomes Measurement (ICHOM) Initiative', JAMA Oncol., vol. 3, no. 5, pp. 677-685, May 2017, doi: 10.1001/jamaoncol.2016.4851.

[17] N. E. Avis, S. Crawford, and J. Manuel, 'Psychosocial problems among younger women with breast cancer', Psychooncology., vol. 13, no. 5, pp. 295-308, May 2004, doi: 10.1002/pon.744.

[18] S. E. Jones et al., 'Comparison of menopausal symptoms during the first year of adjuvant therapy with either exemestane or tamoxifen in early breast cancer: report of a Tamoxifen Exemestane Adjuvant Multicenter trial substudy', J. Clin. Oncol. Off. J. Am. Soc. Clin. Oncol., vol. 25, no. 30, pp. 4765-4771, Oct. 2007, doi: 10.1200/JCO.2007.10.8274.

[19] H. Sung et al., 'Global cancer statistics 2020: GLOBOCAN estimates of incidence and mortality worldwide for 36 cancers in 185 countries', CA. Cancer J. Clin., p. caac.21660, Feb. 2021, doi: 10.3322/caac.21660.

[20] M. Sasaki, M. Parianos, and S. Rahman, 'Top Five Cancer Health Disparities in Florida: Race, Ethnicity, Geographic Location and Socio-Economic Predictors', Univers. J. Public Health, vol. 9, no. 2, pp. 35-50, Apr. 2021, doi: 10.13189/ujph.2021.090202.

[21] J. A. Shell, M. Carolan, Y. Zhang, and K. D. Meneses, 'The longitudinal effects of cancer treatment on sexuality in individuals with lung cancer', Oncol. Nurs. Forum, vol. 35, no. 1, pp. 73-79, Jan. 2008, doi: 10.1188/08.ONF.73-79.

[22] J. B. Reese, R. A. Shelby, and A. P. Abernethy, 'Sexual concerns in lung cancer patients: an examination of predictors and moderating effects of age and gender', Support. Care Cancer Off. J. Multinatl. Assoc. Support. Care Cancer, vol. 19, no. 1, pp. 161-165, Jan. 2011, doi: 10.1007/s00520-010-1000-0.

[23] L. Sarna et al., 'Quality of life and meaning of illness of women with lung cancer', Oncol. Nurs. Forum, vol. 32, no. 1, pp. E9-19, Jan. 2005, doi: 10.1188/05.ONF.E9-E19.

[24] L. Sarna, 'Correlates of symptom distress in women with lung cancer’, Cancer Pract., vol. 1, no. 1, pp. 21-28, Jun. 1993.

[25] A. Lachgar, M. A. Tazi, M. Afif, A. Er-Raki, T. Kebdani, and N. Benjaafar, 'Lung cancer: Incidence and survival in Rabat, Morocco', Rev. DÉpidémiologie Santé Publique, vol. 64, no. 6, pp. 391-395, Dec. 2016, doi: 10.1016/j.respe.2016.02.012.

[26] C. Nejjari et al., 'Translation and validation of European organization for research and treatment of cancer quality of life Questionnaire -C30 into Moroccan version for cancer patients in Morocco', BMC Res. Notes, vol. 7, p. 228, Apr. 2014, doi: 10.1186/1756-0500-7-228.

[27] S. El Fakir et al., 'The Europe an organization for research and treatment of cancer quality of life questionnaire-BR 23 breast cancer-specific quality of life questionnaire: psychometric properties in a Moroccan sample of breast cancer patients', BMC Res. Notes, vol. 7, p. 53, Jan. 2014, doi: 10.1186/1756-0500-7-53.

[28] P. Fayers, N. K. Aaronson, K. Bjordal, M. Groenvold, D. Curran, and A. Bottomley, EORTC QLQ-C30 Scoring Manual. European Organisation for Research and Treatment of Cancer, 2001. Accessed: Feb. 07, 2021. [Online]. Available: https://abdn.pure.elsevier.com/en/publ ications/eortc-qlq-c30-scoring-manual-3rd-edition 
[29] N. K. Aaronson et al., 'The European Organization for Research and Treatment of Cancer QLQ-C30: a quality-of-life instrument for use in international clinical trials in oncology', J. Natl. Cancer Inst., vol. 85, no. 5, pp. 365-376, Mar. 1993, doi: 10.1093/jnci/85.5.365.

[30] J. M. Giesinger et al., 'Replication and validation of higher order models demonstrated that a summary score for the EORTC QLQ-C30 is robust', J. Clin. Epidemiol., vol. 69, pp. 79-88, Jan. 2016, doi: 10.1016/j.jclinepi.2015.08.007.

[31] Delphine KLEIN, quality of life and long-term rehabilitation after breast cancer in ', studylibfr.com. https://studylibfr.com/doc/3855234/qualité-de-vie-et-réins ertion-à-long-terme-après-un-cance... (accessed Aug. 21, 2021).

[32] A. Caravati-Jouveanceaux, 'Do patients cured of colorectal cancer regain a level of quality of life and rehabilitation in the long term comparable to that of population controls?', Phdthesis, University of Franche-Comté, 2012. Accessed: Aug. 21, 2021. [Online]. Available: https://tel.archives-ouvertes.fr/tel-01537998.

[33] P. M. Fayers, 'Interpreting quality of life data: population-based reference data for the EORTC QLQ-C30', Eur. J. Cancer Oxf. Engl. 1990, vol. 37, no. 11, pp. 13311334, Jul. 2001, doi: 10.1016/s0959-8049(01)00127-7.

[34] B. Rahou et al., 'Quality of Life among Moroccan Women Undergoing Treatment of Breast Cancer', Br. J. Med. Med. Res., vol. 21, pp. 1-11, Jan. 2017, doi: 10.9734/BJMMR/2017/33772.

[35] S. El Fakir et al., 'Health-Related Quality of Life among Breast Cancer Patients and Influencing Factors in Morocco', Asian Pac. J. Cancer Prev. APJCP, vol. 17, no. 12, pp. 5063-5069, 2016, doi: 10.22034/APJCP.2016.17.12.5063.

[36] B. Z and E. F. S, 'Health Related Quality of Life in Patients with Lung Cancer in Morocco', Arch. Surg. Oncol., vol. 2, no. 3, 2016, doi: 10.4172/2471-2671.1000113.

[37] Y. Sbitti et al., 'Breast cancer treatment and sexual dysfunction: Moroccan women's perception', BMC Womens Health, vol. 11, no. 1, p. 29, Jun. 2011, doi: 10.1186/1472-6874-11-29.

[38] M. Yassine et al., 'Sexuality of Breast Cancer Patients Treated with Mastectomy', Ann. Oncol., vol. 23, p. ix477, Sep. 2012, doi: 10.1016/S0923-7534(20)34021-7.

[39] J. Mierzynska et al., 'Reference values for the EORTC QLQ-C30 in early and metastatic breast cancer', Eur. J. Cancer, vol. 125, pp. 69-82, Jan. 2020, doi: 10.1016/j.ejca.2019.10.031.

[40] 'reference_values_manual2008.pdf'. Accessed: Sep. 19, 2021. [Online]. Available: https://www.eortc.org/app/uplo ads/sites/2/2018/02/reference_values_manual2008.pdf

[41] K. Härtl, J. Engel, P. Herschbach, H. Reinecker, H. Sommer, and K. Friese, 'Personality traits and psychosocial stress: quality of life over 2 years following breast cancer diagnosis and psychological impact factors', Psychooncology., vol. 19, no. 2, pp. 160-169, Feb. 2010, doi: 10.1002/pon.1536.

[42] R. Khalladi, I. Gargouri, C. Zedini, and H. Ben Saad, 'Quality of life of Tunisian patients with lung cancer: descriptive study', Tunis. Med., vol. 97, no. 5, pp. 626-638, May 2019.

[43] M. Hechtner et al., 'Quality of Life in NSCLC Survivors A Multicenter Cross-Sectional Study', J. Thorac. Oncol., vol. 14, no. 3, pp. 420-435, Mar. 2019, doi: 10.1016/j.jtho.2018.11.019.

[44] J. Ran et al., 'Health-related quality of life in long-term survivors of unresectable locally advanced non-small cell lung cancer', Radiat. Oncol., vol. 12, no. 1, p. 195, Dec. 2017, doi: 10.1186/s13014-017-0909-6.

[45] P. Yang et al., 'Quality of Life and Symptom Burden among Long Term Lung Cancer Survivors: Changing and Adapting', J. Thorac. Oncol. Off. Publ. Int. Assoc. Study Lung Cancer, vol. 7, no. 1, pp. 64-70, Jan. 2012, doi: 10.1097/JTO.0b013e3182397b3e.

[46] S. Iyer, G. Taylor-Stokes, and A. Roughley, 'Symptom burden and quality of life in advanced non-small cell lung cancer patients in France and Germany', Lung Cancer Amst. Neth., vol. 81, no. 2, pp. 288-293, Aug. 2013, doi: 10.1016/j.lungcan.2013.03.008.

[47] M. Stommel, M. E. Kurtz, J. C. Kurtz, C. W. Given, and B. A. Given, 'A Longitudinal Analysis of the Course of Depressive Symptomatology in Geriatric Patients With Cancer of the Breast, Colon, Lung, or Prostate', Health Psychol., vol. 23, no. 6, pp. 564-573, 2004, doi: 10.1037/0278-6133.23.6.564.

[48] D. K. Payne, M. D. Sullivan, and M. J. Massie, 'Women’s psychological reactions to breast cancer', Semin. Oncol., vol. 23, no. 1 Suppl 2, pp. 89-97, Feb. 1996.

[49] M. Panjari, R. J. Bell, and S. R. Davis, 'Sexual function after breast cancer’, J. Sex. Med., vol. 8, no. 1, pp. 294-302, Jan. 2011, doi: 10.1111/j.1743-6109.2010.02034.x.

[50] B. Furlow, 'Sexual dysfunction in patients with lung disease', Lancet Respir. Med., vol. 2, no. 6, p. 439, Jun. 2014, doi: 10.1016/S2213-2600(14)70081-5.

[51] J. Mütsch et al., 'Sexuality and cancer in adolescents and young adults - a comparison between reproductive cancer patients and patients with non-reproductive cancer', BMC Cancer, vol. 19, no. 1, p. 828, Aug. 2019, doi: 10.1186/s12885-019-6009-2.

[52] K. M. Bellizzi et al., 'Positive and negative psychosocial impact of being diagnosed with cancer as an adolescent or young adult', Cancer, vol. 118, no. 20, pp. 5155-5162, Oct. 2012, doi: 10.1002/cncr.27512. 